\title{
Influence of preparation method on structural and magnetic properties of nickel ferrite nanoparticles
}

\author{
BINU P JACOB, ASHOK KUMAR ${ }^{\dagger}$, R P PANT ${ }^{\dagger}$, SUKHVIR SINGH ${ }^{\dagger}$ and \\ E M MOHAMMED* \\ Department of Physics, Maharaja's College, Ernakulam 681 011, India \\ ${ }^{\dagger}$ National Physical Laboratory, New Delhi 110 012, India
}

MS received 15 May 2010

\begin{abstract}
Nickel ferrite nanoparticles of very small size were prepared by sol-gel combustion and co-precipitation techniques. At the same annealing temperature sol-gel derived particles had bigger crystallite size. In both methods, crystallite size of the particles increased with annealing temperature. Sol-gel derived nickel ferrite particles were found to be of almost spherical shape and moderate particle size with a narrow size distribution; while co-precipitation derived particles had irregular shape and very small particle size with a wide size distribution. Nickel ferrite particles produced by sol-gel method exhibited more purity. Sol-gel synthesized nanoparticles were found to be of high saturation magnetization and hysteresis. Co-precipitation derived nickel ferrite particles, annealed at $400^{\circ} \mathrm{C}$ exhibited superparamagnetic nature with small saturation magnetization. Saturation magnetization increased with annealing temperature in both the methods. At the annealing temperature of $600^{\circ} \mathrm{C}$, co-precipitation derived particles also became ferrimagnetic.
\end{abstract}

Keywords. Nickel ferrite; sol-gel technique; co-precipitation; superparamagnetism.

\section{Introduction}

During the last few years, ferrite nanoparticles have drawn major attention because of their technological importance in high density magnetic storage, electronic and microwave devices, telecommunication equipments, magnetic fluids, magnetically guided drug delivery and gas sensors (Murdock et al 1992; Kim et al 2001; Satyanarayana et al 2003; Mishra et al 2006; Rana et al 2007; Kharabe et al 2008). Among various ferrites, which form a major constituent of the magnetic ceramic materials, nanosized nickel ferrite possesses attractive properties for the application as soft magnets, core materials in power transformers and low loss materials at high frequencies (Abraham 1994). High permeability in the radio frequency region, high electrical resistivity, high Curie temperature and low eddy current loss are important properties of nickel ferrites, which make them suitable for wide range of applications (Singhal and Chandra 2007). Being a technologically important material, Niferrites as well as Ni-based mixed ferrites are extensively investigated by various researchers (Mishra et al 2006; Ebrahimi and Azadmanjiri 2007; Zahi et al 2007; Maaz et al 2009).

Nickel ferrite has inverse spinel structure. The crystal structure is face centred cubic with the unit cell contain-

\footnotetext{
*Author for correspondence (emmohammed_2005@yahoo.com)
}

ing $32 \mathrm{O}^{2-}, 8 \mathrm{Ni}^{2+}$ and $16 \mathrm{Fe}^{3+}$ ions. The oxygen ions form 64 tetrahedral and 32 octahedral sites, where 24 cations are distributed. The eight $\mathrm{Ni}^{2+}$ and eight $\mathrm{Fe}^{3+}$ cations occupy half of the octahedral sites and the other eight $\mathrm{Fe}^{3+}$ ions occupy eight tetrahedral sites (Smit and Wijn 1959; Giannakopoulou et al 2002). Ferrimagnetic property of the material arises from magnetic moments of anti-parallel spins between $\mathrm{Fe}^{3+}$ ions at tetrahedral sites and $\mathrm{Ni}^{2+}$ and $\mathrm{Fe}^{3+}$ ions at octahedral sites (Patil and Chougule 2009). The properties of ferrite nanoparticles are influenced by the composition and microstructure which are sensitive to the preparation methodology used. Ferrite nanoparticles are usually prepared by various physical and chemical methods like mechanical milling, inert gas condensation, hydrothermal reaction, ceramic method, sol-gel and co-precipitation techniques etc (Mishra et al 2006; Ebrahimi and Azadmanjiri 2007; Zahi et al 2007; Maaz et al 2009). Sol-gel method has the advantage of good stoichiometric control and the production of ultrafine particles with a narrow size distribution, in a relatively short processing time. Advantages of coprecipitation are the high production rate, very small particle size, low temperature, etc. In order to see the role of different synthesis techniques on the growth, structural morphology and magnetic properties of Ni-ferrite, in the present work, we synthesized ultrafine nickel ferrite nanoparticles by sol-gel and co-precipitation methods and their structural and magnetic properties were thoroughly investigated. 


\section{Experimental}

\subsection{Synthesis}

In sol-gel synthesis, stoichiometric ratios of AR grade ferric nitrate $\left(\mathrm{Fe}\left(\mathrm{NO}_{3}\right)_{3} \cdot 9 \mathrm{H}_{2} \mathrm{O}\right)$ and nickel nitrate $\left(\mathrm{Ni}\left(\mathrm{NO}_{3}\right)_{2} \cdot 6 \mathrm{H}_{2} \mathrm{O}\right)(99.9 \%$ pure MERK) were dissolved in minimum amount of ethylene glycol at room temperature and the sol was heated at $60^{\circ} \mathrm{C}$ to form a wet gel. The gel then dried at $120^{\circ} \mathrm{C}$ self ignites to form $\mathrm{NiFe}_{2} \mathrm{O}_{4}$ powder. The combustion can be considered as a thermally induced redox reaction of the gel wherein ethylene glycol acts as a reducing agent. The nitrate ion acts as an oxidant. The nitrate ion provides an in situ oxidizing environment for the decomposition of the organic component. The obtained powder ground well and two different portions were annealed for $2 \mathrm{~h}$ at 400 and $600^{\circ} \mathrm{C}$, respectively using a carbolite furnace.

In co-precipitation technique, appropriate amount of ferric nitrate and nickel nitrate were dissolved in sufficient amount of de-ionized water. In order to control the $\mathrm{pH}$, three molar sodium hydroxide, which acts as the precipitating agent was added to the solution kept under constant stirring. Brown coloured precipitate formed was filtered and washed several times using de-ionized water until its $\mathrm{pH}$ becomes neutral and dried at $200^{\circ} \mathrm{C}$ for $1 \mathrm{~h}$. The product was then milled in an agate mortar and two different portions were annealed at 400 and $600^{\circ} \mathrm{C}$, respectively for $2 \mathrm{~h}$ to form fine $\mathrm{Ni}$-ferrite nanoparticles.

\subsection{Characterization}

The crystalline phases of the prepared samples were identified by X-ray diffraction (XRD) technique using RIGAKU make RINT 2000 powder X-ray diffractometer with $\mathrm{CuK} \alpha$ radiation $(\lambda=1.54059 \AA)$ at $40 \mathrm{kV}$ and $30 \mathrm{~mA}$. Scanning was performed from $20^{\circ}$ to $70^{\circ}$ at a step size of $0.02 \%$ for each sample. The crystal structure, lattice parameter, crystallite size and X-ray density were determined. Elemental analysis of the samples prepared by both methods was carried out using energy dispersive X-ray spectroscopy (EDX) (OXFORD-INCAENERGY 250). The Fourier transform infrared (FTIR) absorption spectra of the samples were recorded using FTIR spectrometer (Thermo Nicolet, Avatar 370) in the wave number range $4000-400 \mathrm{~cm}^{-1}$ with potassium bromide $(\mathrm{KBr})$ as solvent. High resolution transmission electron microscope (HRTEM, TECHNAI G ${ }^{2}$ F30 STWIN) operated at $300 \mathrm{kV}$ was used to investigate the morphology and particle size of the synthesized Ni-ferrite samples. Magnetic characterization was carried out using vibrating sample magnetometer (VSM, PAR EG\&G 4500 ) at room temperature up to a maximum field of $15 \mathrm{kOe}$.

\section{Results and discussion}

Figure 1 shows XRD patterns of $\mathrm{NiFe}_{2} \mathrm{O}_{4}$ (a) coprecipitation derived samples and (b) sol-gel derived samples. The patterns were compared with standard data (JCPDS PDF card No. 074-2081) and the formation of single phase cubic $\mathrm{NiFe}_{2} \mathrm{O}_{4}$ nanoparticles in all the samples was confirmed. Sol-gel derived sample annealed at $600^{\circ} \mathrm{C}$ shows some extra peaks (figure 1b) indicating the formation of hematite $\left(\mathrm{Fe}_{2} \mathrm{O}_{3}\right)$ at this temperature. The mean crystallite sizes of particles were calculated for all samples using Scherrer formula (Cullity 1978). The average crystallite sizes of the samples are tabulated in table 1. It is obvious from the table that co-precipitation yields Ni-ferrite nanoparticles with less crystallite size compared with sol-gel synthesis. Similar results were reported earlier in the case of magnesium ferrite (Liu et al 2007). At the annealing temperature of $600^{\circ} \mathrm{C}$, both the
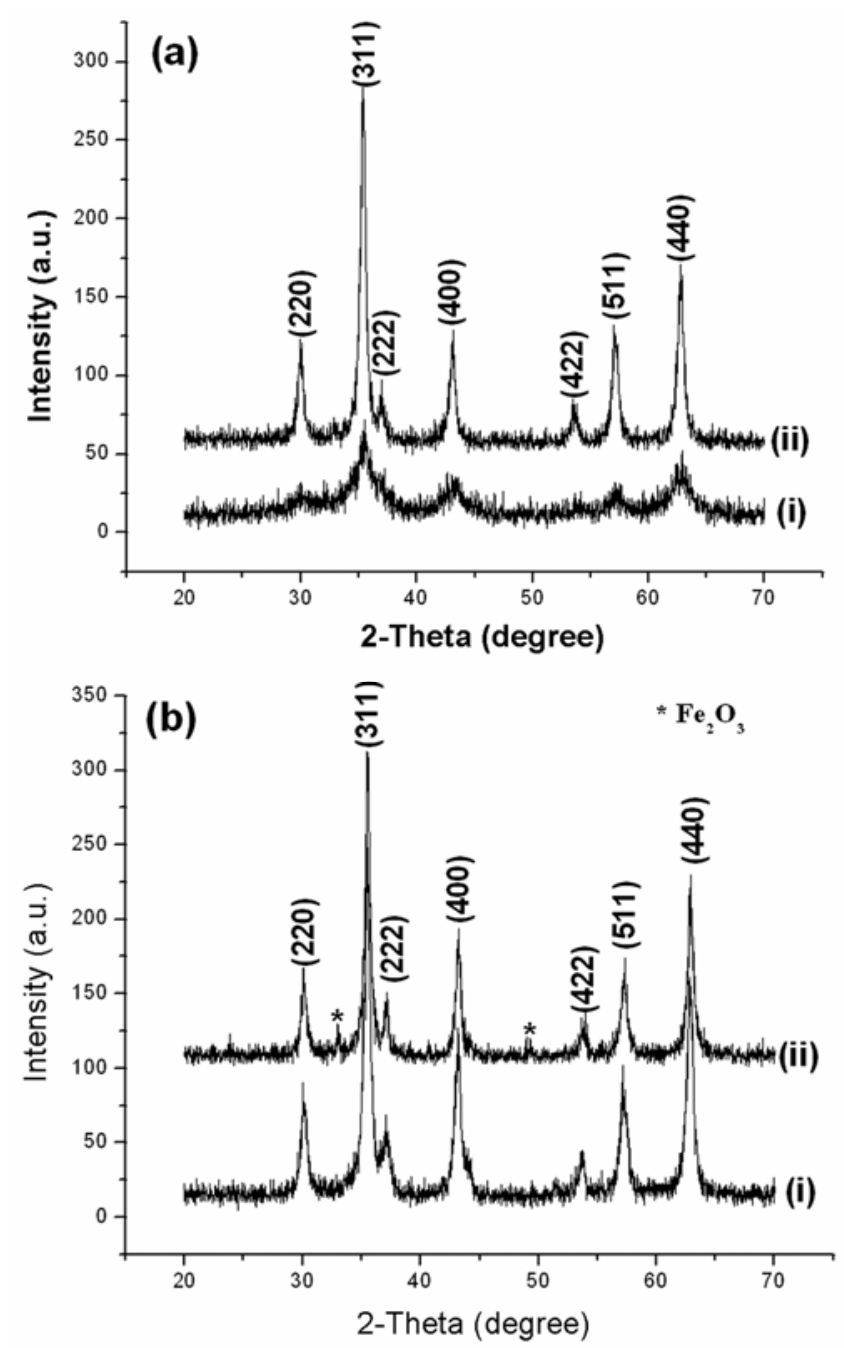

Figure 1. X-ray diffraction patterns of $\mathrm{NiFe}_{2} \mathrm{O}_{4}$ nanoparticles prepared by (a) co-precipitation, annealed at (i) $400^{\circ} \mathrm{C}$ and (ii) $600^{\circ} \mathrm{C}$ and (b) sol-gel, annealed at (i) $400^{\circ} \mathrm{C}$ and (ii) $600^{\circ} \mathrm{C}$. 
Table 1. XRD analysis and magnetic characterization results of $\mathrm{NiFe}_{2} \mathrm{O}_{4}$ samples.

\begin{tabular}{lcccccrr}
\hline $\begin{array}{l}\text { Preparation } \\
\text { technique }\end{array}$ & $\begin{array}{c}\text { Annealed } \\
\text { temperature }\left({ }^{\circ} \mathrm{C}\right)\end{array}$ & $\begin{array}{c}\text { Crystallite } \\
\text { size }(\mathrm{nm})\end{array}$ & $\begin{array}{c}\text { X-Ray } \\
\text { density }(\mathrm{g} / \mathrm{cc})\end{array}$ & $\begin{array}{c}\text { Lattice } \\
\text { constant }(\AA)\end{array}$ & $\begin{array}{c}\text { Saturation } \\
\text { magnetization } \\
M_{\mathrm{S}}(\mathrm{emu} / \mathrm{g})\end{array}$ & $\begin{array}{c}\text { Remanence } \\
M_{\mathrm{R}}(\mathrm{emu} / \mathrm{g})\end{array}$ & $\begin{array}{c}\text { Coercivity } \\
H_{\mathrm{C}}(\mathrm{Oe})\end{array}$ \\
\hline Sol-gel & 400 & $15 \cdot 100$ & $5 \cdot 2831$ & $8 \cdot 3807$ & $30 \cdot 8377$ & $3 \cdot 2500$ & $86 \cdot 6648$ \\
& 600 & $16 \cdot 700$ & $5 \cdot 2790$ & $8 \cdot 3711$ & 31.6259 & $3 \cdot 8800$ & 113.9953 \\
Co-precipitation & 400 & $5 \cdot 165$ & $5 \cdot 2862$ & $8 \cdot 3720$ & $14 \cdot 2219$ & - & - \\
& 600 & $15 \cdot 009$ & $5 \cdot 2201$ & 8.3804 & $30 \cdot 8990$ & 1.5854 & $38 \cdot 7849$ \\
\hline
\end{tabular}

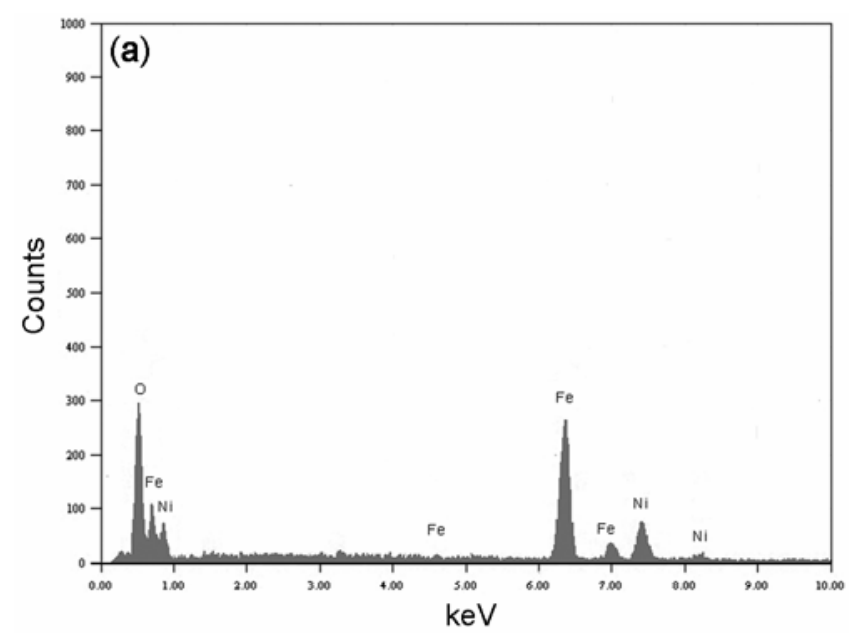

(b)

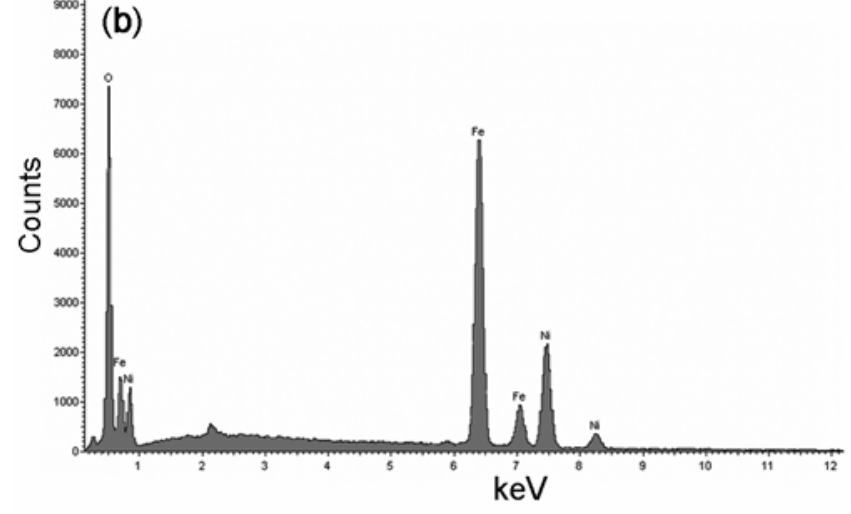

Figure 2. EDX spectra of $\mathrm{NiFe}_{2} \mathrm{O}_{4}$ nanoparticles prepared by (a) co-precipitation and (b) sol-gel technique.

methods give almost the same crystallite size. Thus solgel derived particles attain better crystallinity even at lower annealing temperature. In sol-gel as well as coprecipitation, the crystallite size was observed to be increasing with temperature. It was reported earlier that annealing process generally decreases lattice defects and strains; however, it can also cause coalescence of smaller grains that results in an increase in the average grain size of nanoparticles (Raming et al 2002). The actual (X-ray) density of $\mathrm{NiFe}_{2} \mathrm{O}_{4}$ nanoparticles is calculated using the formula (Khan et al 2009)

$$
P_{\mathrm{x}}=8 M / N a^{3} \text {, }
$$

and is given in table 1 . Where $M$ is the molecular weight $(\mathrm{kg})$ of the sample, $N$ the Avogadro's number (per mol) and $a$ the lattice constant ( $\AA$ ). X-ray density is observed to be less than that reported for nickel ferrite produced by ceramic technique; but it is greater than physical density of Ni-ferrite which is in accordance with literature (Khan et al 2009). Calculated values of lattice parameter of $\mathrm{Ni}$ ferrite samples are listed in table 1 , which are in close agreement with standard data (8.34 ̊) (Smit and Wijn 1959).

The stoichiometry of the powder samples in both the methods was checked by EDX analysis. EDX patterns of the samples are shown in figure 2 and composition of the elements present is given in table 2. Sol-gel derived sample shows expected stoichiometry; while co-precipitation derived sample indicates nickel deficiency and the presence of excess oxygen. Co-precipitation yields $\mathrm{NiFe}_{2} \mathrm{O}_{4}$ particles of very small size and hence specific surface area of the particles becomes very large. So the possibility of oxygen adsorption is high and this may be the reason for excess oxygen (Yang et al 2005). No trace of any impurity was found which indicates purity of the samples.

Morphology and particle size of the synthesized samples were investigated using HRTEM. Figure 3 shows HRTEM images of Ni-ferrite nanoparticles synthesized by (a) co-precipitation and (b) sol-gel techniques, annealed at $400^{\circ} \mathrm{C}$. From figure $3(\mathrm{a})$ it is observed that sol-gel derived particles are slightly agglomerated with almost spherical shape and a particle size of $18-25 \mathrm{~nm}$, which confirm the XRD analysis. Co-precipitation derived particles are of irregular shape with a wide particle size distribution of $8-20 \mathrm{~nm}$. Thus, it is evident that solgel synthesis gives $\mathrm{Ni}$-ferrite particles of moderate size and a narrow particle size distribution.

FTIR spectral analysis helps to confirm the formation of spinel structure in ferrite samples. The FTIR spectra of the investigated $\mathrm{NiFe}_{2} \mathrm{O}_{4}$ samples are shown in figure 4 . In the wavenumber range of $1000-300 \mathrm{~cm}^{-1}$, two main broad metal-oxygen bands are seen in the infrared spectra of all spinels, especially ferrites. The higher one $\left(v_{1}\right)$ generally observed in the range $600-550 \mathrm{~cm}^{-1}$, is caused by the stretching vibrations of the tetrahedral metaloxygen bond. The lowest band $\left(v_{2}\right)$ usually observed in the range $450-385 \mathrm{~cm}^{-1}$, is caused by the metal-oxygen 
vibrations in the octahedral sites (Waldron 1955). The vibrational frequencies of IR bands $v_{1}$ and $v_{2}$ of samples prepared by both co-precipitation and sol-gel are given in table 3, which are in perfect agreement with reported values (Montemayor et al 2007; Priyadharsini et al 2009).
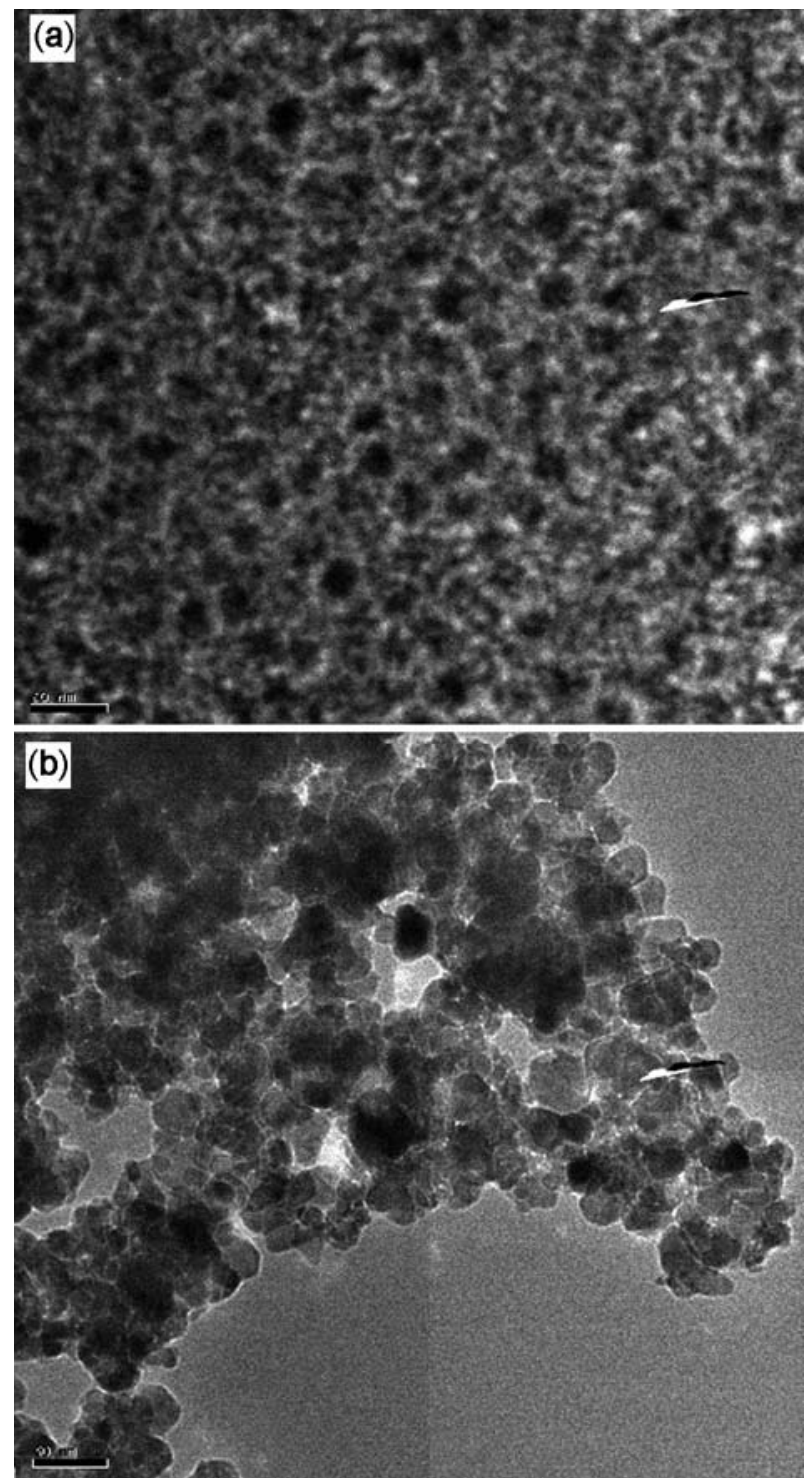

Figure 3. TEM micrograph of $\mathrm{NiFe}_{2} \mathrm{O}_{4}$ nanoparticles prepared by (a) co-precipitation, annealed at $400^{\circ} \mathrm{C}$ and (b) sol-gel technique, annealed at $400^{\circ} \mathrm{C}$.

Table 2. EDX results of $\mathrm{NiFe}_{2} \mathrm{O}_{4}$ samples prepared by co-precipitation and sol-gel techniques.

\begin{tabular}{lccccc}
\hline & \multicolumn{2}{c}{ Co-precipitation } & & \multicolumn{2}{c}{ Sol-gel } \\
\cline { 2 - 3 } \cline { 5 - 6 } Element present & Expected & EDX & & Expected & EDX \\
\hline $\mathrm{Ni}$ & 1 & 0.4529 & & 1 & 0.9933 \\
$\mathrm{Fe}$ & 2 & 1.3678 & & 2 & 1.8865 \\
$\mathrm{O}$ & 4 & $5 \cdot 1793$ & & 4 & 4.1209 \\
\hline
\end{tabular}

The spectra show prominent bands near 3400 and $1600 \mathrm{~cm}^{-1}$, which are attributed to the stretching modes and $\mathrm{H}-\mathrm{O}-\mathrm{H}$ bending vibrations of the free or absorbed water. The band near $1400 \mathrm{~cm}^{-1}$ is due to the antisymmetric NO-stretching vibrations arising from the nitrate group which is present as residue in the samples (Priyadharsini et al 2009). This band is very weak in the spectra of sol-gel derived sample, indicating the purity of $\mathrm{Ni}$-ferrite nanoparticles synthesized by this method.

Magnetic characterization of the samples was performed by VSM at room temperature with a maximum applied field of $15 \mathrm{kOe}$. Figure 5 shows typical magnetic hysteresis loops of Ni-ferrite samples prepared by (a) coprecipitation, annealed at $400^{\circ} \mathrm{C}$, (b) co-precipitation, annealed at $600^{\circ} \mathrm{C}$, (c) sol-gel, annealed at $400^{\circ} \mathrm{C}$ and (d) sol-gel, annealed at $600^{\circ} \mathrm{C}$. It is obvious from the figure that saturation magnetization $\left(M_{\mathrm{S}}\right)$ is not attained even in the maximum field of $15 \mathrm{kOe}$. The $M_{\mathrm{S}}$ values of all the samples were calculated by extrapolating the inverse of the field vs magnetization $(M)$ graph to $1 / H=0$ (Kale et al 2004). The saturation magnetization $\left(M_{\mathrm{S}}\right)$, coercivity $\left(H_{\mathrm{C}}\right)$ and remanence $\left(M_{\mathrm{R}}\right)$ of all the samples are given in table 1. It is observed that co-precipitation derived $\mathrm{Ni}$ ferrite particles annealed at $400^{\circ} \mathrm{C}$ do not exhibit hysteresis with almost immeasurable remanence and coercivity. This is a unique property of superparamagnetism (LesliePelecky and Riek 1996). When annealed at $600^{\circ} \mathrm{C}$,

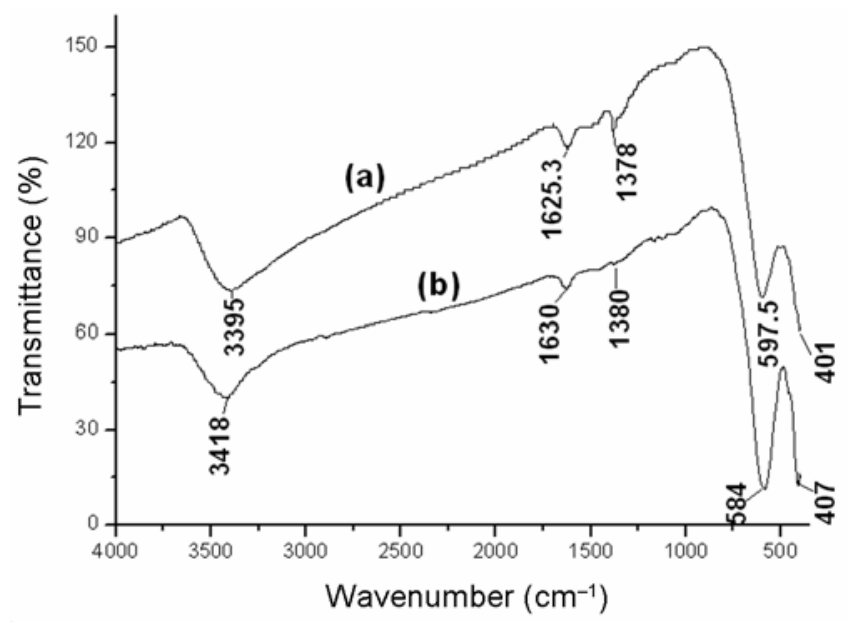

Figure 4. FTIR spectra of Ni-ferrite nanoparticles, annealed at $400^{\circ} \mathrm{C}$ prepared by (a) co-precipitation method and (b) solgel technique.

Table 3. FTIR frequency bands of $\mathrm{NiFe}_{2} \mathrm{O}_{4}$ samples.

\begin{tabular}{lcc}
\hline & \multicolumn{2}{c}{ IR frequency bands $\left(\mathrm{cm}^{-1}\right)$} \\
\cline { 2 - 3 } Preparation technique & $V_{1}$ & $V_{2}$ \\
\hline Co-precipitation & 401 & $597 \cdot 5$ \\
Sol-gel & 407 & 584 \\
\hline
\end{tabular}



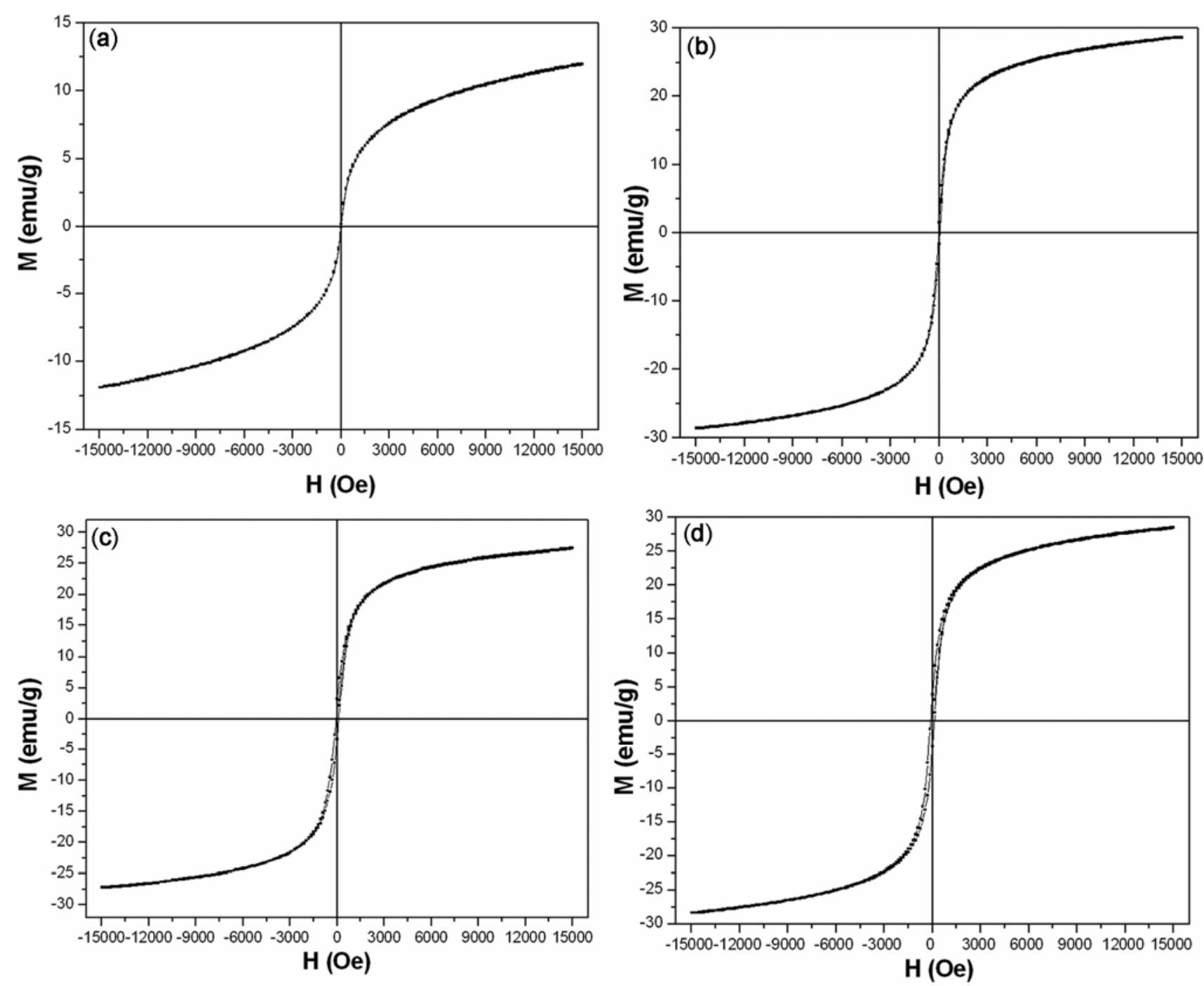

Figure 5. Room temperature hysteresis loop of $\mathrm{NiFe}_{2} \mathrm{O}_{4}$ nanoparticles prepared by (a) co-precipitation, annealed at $400^{\circ} \mathrm{C}$, (b) co-precipitation, annealed at $600^{\circ} \mathrm{C}$, (c) sol-gel technique, annealed at $400^{\circ} \mathrm{C}$ and (d) sol-gel technique, annealed at $600^{\circ} \mathrm{C}$.

co-precipitation derived particles also exhibit hysteresis. This is expected since at higher temperature, there is increase in particle size as it is clear from XRD analysis. Co-precipitation derived sample annealed at $600^{\circ} \mathrm{C}$ has very small $M_{\mathrm{R}}$ and $H_{\mathrm{C}}$ values but almost equal $M_{\mathrm{S}}$ value compared with the corresponding sol-gel derived sample. Sol-gel derived samples are ferrimagnetic with moderately high saturation magnetization. Comparatively low of $M_{\mathrm{S}}$ value of sol-gel derived sample annealed at $600^{\circ} \mathrm{C}$ may be due to the presence of $\mathrm{Fe}_{2} \mathrm{O}_{3}$. The low value of saturation magnetization compared with that of bulk Ni-ferrite (56 emu/g) (Maaz et al 2009) can be understood on the basis of core-shell model, which explains that the finite size effects of the nanoparticles lead to a canting of spins on their surface and thereby reduces its magnetization (Kodama 1999; Priyadharsini et al 2009).

\section{Conclusions}

Co-precipitation and sol-gel techniques have been used to synthesize $\mathrm{NiFe}_{2} \mathrm{O}_{4}$ nanoparticles. Both the methods produce single phase cubic Ni-ferrite nanoparticles; but sol-gel derived particles annealed at $600^{\circ} \mathrm{C}$ exhibits hematite $\left(\mathrm{Fe}_{2} \mathrm{O}_{3}\right)$ phase also. Co-precipitation gives particles of very small size with a wide size variation (8$20 \mathrm{~nm}$ ) and superparamagnetic nature. Sol-gel combustion produces Ni-ferrite particles of comparatively larger size with small size variation $(18-25 \mathrm{~nm})$ and ferrimagnetic nature. As the annealing temperature is increased, particle size and saturation magnetization are found to increase in both the methods. Co-precipitation derived sample also exhibits hysteresis at the annealing temperature of $600^{\circ} \mathrm{C}$. Sol-gel method is better for the preparation of homogeneous, pure and compositionally 
stoichiometric ferrites. Co-precipitation is suitable for the synthesis of ferrites with very small size and superparamagnetic nature. At the same annealing temperature, coprecipitation derived $\mathrm{NiFe}_{2} \mathrm{O}_{4}$ nanoparticles exhibit less hysteresis loss with almost same saturation magnetization.

\section{Acknowledgement}

One of the authors (BPJ) is grateful to the University Grants Commission, New Delhi, for providing a FIP fellowship. (EMM) thanks UGC for financial support for this research work.

\section{References}

Abraham T 1994 Am. Ceram. Soc. Bull. 7362

Cullity B D 1978 Elements of X-ray diffraction (California: Addison-Wesley) 2nd edn, p. 102

Ebrahimi S A S and Azadmanjiri J 2007 J. Non-Cryst. Solids 353802

Giannakopoulou T, Kompotiatis L, Kontogeorgakos A and Kordas G 2002 J. Magn. Magn. Mater. 246360

Kale A, Gubbala S and Misra R D K 2004 J. Magn. Magn. Mater. 277350

Khan M A, Islam M U, Rahman I Z, Genson A and Hampshire S 2009 Mater. Charact. 6073

Kharabe R G, Devan R S, Kanamadi C M and Chougule B K 2008 J. Alloys Compds $\mathbf{4 6 3} 67$
Kim Woo Chul, Kim Sam Jin, Lee Seung Wha and Kim Chul Sung 2001 J. Magn. Magn. Mater. 2261418

Kodama R H 1999 J. Magn. Magn. Mater. 200359

Leslie-Pelecky Diandra L and Riek Reuben D 1996 Chem. Mater. 81770

Liu Cui Ping, Li M W, Cui Z, Haung J R, Tian Y L, Lin T and Mi W B 2007 J. Mater. Sci. 426133

Maaz K, Karim S, Mumtaz A, Hasanain S K, Liu J and Duan J L 2009 J. Magn. Magn. Mater. 3211838

Mishra S, Karak N, Kundu T K, Das D, Maity N and Chkravorty D 2006 Mater. Letts 601111

Montemayor S M, Garcia-Cerda L A, Torres-Lubian J R and Fernandez O S R 2007 J. Sol-Gel Sci. Technol. 42181

Murdock E S, Simmons R F and Davidson R 1992 IEEE Trans. Magn. 283078

Patil D R and Chougule B K 2009 Mater. Chem. Phys. 11735

Priyadharsini P, Pradeep A, Rao P S and Chandrasekaran G 2009 Mater. Chem. Phys. 116207

Raming T P, Winnubst A J A, Van Kats C M and Philipse P 2002 J. Colloid Interf. Sci. 249346

Rana S, Gallo A, Srivastava R S and Misra R D K 2007 Acta Biomater. 3233

Satyanarayana L, Madhusudan Reddy K and Manorama S V 2003 Mater. Chem. Phys. 8221

Singhal S and Chandra K 2007 J. Solid State Chem. 180296

Smit J and Wijn H P J 1959 Ferrites (The Netherlands: Philips Technical Library) p. 137

Waldron R D 1955 Phys. Rev. 991727

Yang Liufang, Xie Yongan, Zhao Heyun, Wu Xinghui and Wang Yude 2005 Solid-State Electron. 491029

Zahi S, Doud A R and Hashim M 2007 Mater. Chem. Phys. 106 452 